\title{
The impact of quarantine duration on psychological outcomes and vaccination intention during the second outbreak of COVID-19 in China
}

\author{
Lele Chen ( $\square$ lelechen0514@163.com ) \\ Nanjing University \\ Yuxin Xia \\ Hebei Normal University \\ Dingding Wang \\ Nanjing University \\ Renlai Zhou \\ Nanjing University
}

Research Article

Keywords: COVID-19, Psychological distress, wellbeing, social distancing, vaccination intention

Posted Date: March 11th, 2021

DOI: https://doi.org/10.21203/rs.3.rs-317935/v1

License: (1) This work is licensed under a Creative Commons Attribution 4.0 International License. Read Full License 


\section{Abstract \\ Objectives}

A second outbreak of COVID-19 happened in China. We assessed the impact of quarantine duration on psychological outcomes and vaccination intention.

\section{Methods}

A cross-sectional online survey was employed. Participants were invited to complete the measurement of quarantine duration, social distancing, psychological distress, wellbeing (WHO-5), and vaccination intention. Multiple linear and logistic regression was used to examine the relationship between quarantine duration and social distancing, psychological distress, wellbeing, as well as vaccination intention.

\section{Results}

Of the 944 participants, $17.2 \%$ ( $7.8 \%$ quarantined for $1-7$ days and $9.4 \%$ quarantined for $>7$ days) of the sample have been quarantined. Quarantine for $1-7$ days raised the social distancing $(\beta=2.6195 \% \mathrm{Cl} 1.90-3.33)$ and vaccination intention $(\mathrm{OR}=2.1695 \% \mathrm{Cl} 1.22-3.82)$ .While quarantine for $>7$ days was associated with the increases the social distancing $(\beta=3.0095 \% \mathrm{Cl} 2.37-3.64)$ and psychological distress $(\beta=1.0395 \% \mathrm{Cl} 0.22-1.86)$, and the decrease of wellbeing $(\beta=1.2795 \% \mathrm{Cl} 0.29-2.26)$.

\section{Conclusions}

Longer quarantine duration reported a greater impact on social distancing and psychological distress, and a poorer wellbeing during the second COVID-19 pandemic. Quarantine for 1-7 days associated with the increase of vaccination intention. The duration of quarantine should be considered when preparing for immunization programs and preventing psychological disorders during COVID-19 pandemic.

\section{Introduction}

COVID-19 initially broke out in Wuhan, China, from December 2019 to March 2020(Li, 2020). Although the epidemic abated in China, a second outbreak happened from December 2020 in several provinces or cities in China such as Beijing, Hebei, and Liaoning (George, 2021; Xinhua, 2021). A lockdown has been firstly imposed on Hebei's capital city Shijiazhuang to contain the spread of the COVID-19 on January 7, 2021 (Daily, 2021). The second pandemic of mental health crises may be existed during the quarantine (Xiang et al., 2020). However, it is lack of the empirical evidence that how quarantine impacts mental health during the second COVID-19 pandemic. In addition, COVID-19 vaccines have been available on December 31, 2020 (Daily, 2020), whether quarantine influences vaccination intention is still an open question. Thus, it is emergent and necessary to explore the association between quarantine and vaccination intention as well as mental health during the second pandemic.

Evidences suggested that quarantine might be an effective way to contain the spread of the COVID-19 in China and other countries being affected(Pan et al., 2020), especially in the absence of a vaccine or effective treatment. However, quarantine has some significant downsides. Previous studies have reported the direct consequences of quarantine including the increases of the social distancing, Ioneliness, and mental disorders(Luchetti et al., 2020; Pfefferbaum and North, 2020; Venkatesh and Edirappuli, 2020). A cross-sectional study conducted in Wuhan showed that $21.7 \%$ of teenagers restricted in home reported having anxiety and $24.6 \%$ for depression(Li et al., 2021). Another cross-sectional study conducted at the first outbreak in China demonstrated that quarantine was associated with increased risk of total psychological outcomes(Wang et al., 2021). However, the duration of quarantine was not mentioned in this study. A recent review study analyzed the psychological impact of quarantine and revealed that quarantined people reported negative psychological effects including stress symptoms, confusion, and anger(Brooks et al., 2020). Notably, only 3 papers out of 24 in this review explored the impact of quarantine duration on psychological outcomes. Moreover, most of the papers collected the evidences during the 2003 outbreak of severe acute respiratory syndrome (SARS) and the 2014 Ebola outbreak. Although the authors highlighted that the quarantine duration may be responsible for the negative psychological repercussions of the quarantine, the association between quarantine duration and psychological health need to be further studied during COVID-19 pandemic. 
Vaccination has been considered as the most effective way against the spread of COVID-19 in public health. The catastrophic consequences associated with COVID-19 have increased the need for taking an effective vaccine. When some vaccines are in clinical trials, a global survey showed that $90 \%$ of participants had vaccination intention in China, the rate was higher than other countries such as Russia(Lazarus et al., 2020). While the vaccines became available and the second outbreak happened in China, whether the acceptance ratio can keep this high level is still an open question. Moreover, a lot of previous studies focused on some psychological or socioeconomic factors influencing vaccination intention instead of the impact of quarantine on acceptance ratio of COVID-19 vaccine(Prasetyo et al., 2020; Sherman et al., 2020; Wang et al., 2020). Estimating the relationship between quarantine duration between vaccination intention will be helpful to ensure large-scale, equitable access and distribution of a COVID-19 vaccine.

The aim of this study is to estimate the psychological outcomes and vaccination intension during the second outbreak of COVID-19 in China. We tested the relationship between quarantine duration and vaccination intention as well as psychological outcomes including social distancing, psychological distress, and wellbeing. This information is critical to preparing well for future immunization programs against COVID-19 and preventing psychological disorders during COVID-19 pandemic.

\section{Methods And Materials}

\subsection{Participants}

This online cross-sectional study was conducted from January 10 to January 23, 2021, while the second outbreak of COVID-19 was happened in China, and people were under state-enforced strict quarantine. Participants were invited to participate in this web-based anonymous survey by scanning QR code or clicking the linkage on Wechat. Self-reported questionnaires were administered to participants through the Wenjuanxing platform (Changsha Haoxing Information Technology Co., Ltd., China). Finally, our electronic questionnaire was clicked 1002 times. The inclusion criteria were being a Chinese citizen and at least 18 years of age. We excluded participants aged less than 18 years old and incomplete response.

Ultimately, 944 participants were included in our study.

The response rate was $94.2 \%$. Among the included participants, $43.4 \%(n=410)$ participants were from Hebei province, $16.0 \%(n=151)$ were from Beijing city, and $18.4 \%(n=174)$ were from Liaoning province. No monetary compensation was provided to the participants. The study procedures were approved by the body for ethical evaluation of research projects at the Department of Psychology-part of the School for Social and Behavioral Sciences at Nanjing University, China.

All participants provided written informed consent.

\subsection{Measures}

\subsubsection{Quarantine duration}

Quarantine duration was measured by two questions. The first question was about "Are you being quarantined during the COVID-19 pandemic". The second question was about "How long have you been quarantined". Quarantine duration were categorized into three groups: 0 days, $1-7$ days, and $>7$ days.

\subsubsection{Social distancing}

Social distancing was determined from three questions concerning the coronavirus situation(Kim and Jung, 2021). The questions mentioned the frequency of someone staying at home, not attending social gatherings, and keeping a distance of at least two meters to other people for the past week based on a five-point scale, ranging from 1 (Never) to 5 (Always). The total scores were summed in the current study. The total scores range from 3 to 15. The scale had an acceptable Cronbach's alpha score of 0.77 .

\subsubsection{COVID-19 related psychological distress}

COVID-19 related psychological distress was measured based on prior reference(Kim and Jung, 2021). The following 5 items were asked to reflect participants' psychological state during COVID-19 pandemic: 1) I am nervous when I think about current circumstances; 2) I am calm and relaxed; 3) I am worried about my health; 4) I am worried about the health of my family members; and 5) I feel stressed about leaving my house. Answers were coded on a 5-point scale, ranging from 1 (does not apply at all) to 5 (Strongly applies), to indicate the extent to which each statement applied to the participant. Total scores of the psychological distress range from 5 to 25 . The scale had an acceptable Cronbach's alpha score of 0.77 .

\subsubsection{Wellbeing}


The World Health Organization-Five Well-Being Index (WHO-5) was used in the current study to measure wellbeing(Topp et al., 2015). The WHO- 5 consists of 5 positive items: "I have felt cheerful in good spirits;" "I have felt calm and relaxed;" "I have felt active and vigorous;" "I woke up feeling fresh and rested;" and "My daily life has been filled with things that interest me." The extent to which the positive feelings were present in the last two weeks is scored on

a 6-point Likert scale ranging from 0 (at no time) to 5 (all of the time). The total scores range from 0 to 25 . The scale had a good internal consistency reliability $a=0.91$ in this study.

\subsubsection{Vaccination intention}

The COVID-19 vaccination intention was measured using a one-item question: "The vaccine against COVID-19 infection has been available in the market, would you take it?". The answer was a five-point scale from "Definitely not" to "Definitely". The participants who answered "Definitely", or "Probably" were regarded as having an intention to take vaccine. However, the participants who answered "Possibly", "Probably not", or "Definitely not" showed no intention to take vaccine.

\subsubsection{Covariates}

The covariates covered demographic characteristics and health status. Demographic variables included gender (male or female), age (in years), residence (rural or urban), marriage status (married or unmarried), education (secondary and below or tertiary), and monthly percapita income ( $\leq 1000$ yuan, 1001-3000 yuan, 3001-5000 yuan, or $>5000$ yuan). Health status was measured by self-reported health status (fair/poor, good, or very good) and whether the participants had chronic diseases. The participants who had cardiovascular diseases, diabetes, hepatitis B, chronic obstructive pulmonary disease, chronic kidney diseases, or cancer were defined as having chronic diseases.

\subsection{Statistical analyses}

Frequency and mean were used to describe the characteristics of the study sample. Chi-square tests and $F$-test were used to compare the demographic differences among participants with different quarantine duration. One-way ANOVA or Chi-square test was used to explore the associations between quarantine duration and vaccination intention, social distancing, psychological distress as well as wellbeing. Logistic regression was used to examine the association between quarantine duration and vaccination after adjusting for covariates. Odds ratio $(\mathrm{OR})$ and $95 \%$ confidence intervals $(95 \% \mathrm{Cl})$ were computed. Multiple linear regression was used to examine the association between quarantine duration and social distancing, psychological distress as well as wellbeing after adjusting for covariates. To show adjusted standardized difference of social distancing, psychological distress, and wellbeing among different quarantine duration, forest plot was made based on the multiple linear regression. Adjusted standardized score and $95 \% \mathrm{Cl}$ were calculated. Analyses were performed in Stata version 15 (Stata Corp, College Station, Texas) and R version 3.4.3 (R Development Core Team, 2018). We considered a two-sided $\mathrm{P}$ value of less than 0.05 to be significant.

\section{Results}

\subsection{Characteristics of the study sample}

Of the 944 participants, $17.2 \%(n=162)$ of the sample have been quarantined during the COVID-19 pandemic, $9.4 \%(n=93)$ have been quarantined for at least 7 days. Table 1 shows more than half of the sample were female (72.9\%), came from urban areas (65.8\%), were unmarried (53.8\%), and had university degrees (89.0\%). The average age was 32.7 years old. With respect to health status, a small proportion reported their health status as poor/fair (28.7\%) and $8.8 \%$ reported having chronic diseases. In addition, participants who have been quarantined were younger $(P<0.001)$, and unmarried $(P=0.001)$. 
Table 1

Characteristics of the study population stratified by quarantine duration

\begin{tabular}{|c|c|c|c|c|c|}
\hline & \multirow[t]{2}{*}{ Overall N(\%) } & \multicolumn{3}{|c|}{ Quarantine duration (Days, N, \%) } & \multirow[t]{2}{*}{$P$ value } \\
\hline & & $0(\mathrm{~N}=782)$ & $1-7(N=69)$ & $>7(\mathrm{~N}=93)$ & \\
\hline Gender & & & & & 0.150 \\
\hline Male & $256(27.1)$ & $220(85.9)$ & $12(4.7)$ & $24(9.4)$ & \\
\hline Female & $688(72.9)$ & $562(81.7)$ & $57(8.3)$ & $69(10.0)$ & \\
\hline Age, mean(SD),years & $32.7 \pm 13.0$ & $33.4 \pm 13.3$ & $32.7 \pm 12.3$ & $27.3 \pm 9.6$ & $<0.001$ \\
\hline Residence & & & & & 0.099 \\
\hline Urban & $621(65.8)$ & $511(82.3)$ & $53(8.5)$ & $57(9.2)$ & \\
\hline Rural & $323(34.2)$ & $271(83.9)$ & $16(5.0)$ & $36(11.1)$ & \\
\hline Marriage & & & & & 0.001 \\
\hline Unmarried & $508(53.8)$ & 406(79.9) & $35(6.9)$ & $67(13.2)$ & \\
\hline Married & $436(46.2)$ & $376(86.2)$ & $34(7.8)$ & $26(6.0)$ & \\
\hline Education & & & & & 0.903 \\
\hline Secondary and below & 104(11.0) & $87(83.7)$ & $8(7.7)$ & $9(8.6)$ & \\
\hline Tertiary & $840(89.0)$ & $695(82.7)$ & $61(7.3)$ & $84(10.0)$ & \\
\hline Monthly per-capita inco & me (Yuan) & & & & $<0.001$ \\
\hline$\leq 1000$ & $140(14.8)$ & 111(79.3) & $9(6.4)$ & $20(14.3)$ & \\
\hline $1001-3000$ & $286(30.3)$ & $224(78.3)$ & $20(7.0)$ & $42(14.7)$ & \\
\hline $3001-5000$ & $225(23.8)$ & $185(82.2)$ & $19(8.4)$ & $21(9.3)$ & \\
\hline$>5000$ & 293(31.1) & 262(89.4) & $21(7.2)$ & $10(3.4)$ & \\
\hline Self-reported health & & & & & 0.661 \\
\hline Fair/Poor & $271(28.7)$ & $231(85.2)$ & $18(6.6)$ & $22(8.2)$ & \\
\hline Good & $482(51.1)$ & $396(82.2)$ & $34(7.1)$ & $52(10.8)$ & \\
\hline Very good & $191(20.2)$ & $155(81.2)$ & $17(8.9)$ & 19(9.9) & \\
\hline Chronic diseases & & & & & 0.155 \\
\hline No & $861(91.2)$ & $707(82.1)$ & $65(7.5)$ & $89(10.4)$ & \\
\hline Yes & $83(8.8)$ & $75(90.4)$ & $4(4.8)$ & $4(4.8)$ & \\
\hline
\end{tabular}

\subsection{Univariate analyses of the association between quarantine duration and psychological outcomes and vaccination intention}

Table 2 shows the univariate analyses of the association between quarantine duration and social distancing, psychological distress, wellbeing as well as vaccination intention. One-way ANOVA analyses demonstrates that quarantine duration influenced social distancing $(P<0.001)$, psychological distress $(P=0.003)$, and wellbeing $(P=0.016)$. The least significant difference $(L S D)$ test shows that participants who have been quarantined for $>7$ days had the largest social distancing (13.3 \pm 1.9$)$ and psychological distress (17.2 \pm 3.8$)$ as well as the poorest wellbeing $(15.2 \pm 5.4)$ compared to those without quarantine. On the whole, $62.1 \%$ of the sample had an intention to take COVID-19 vaccine, while $37.9 \%$ did not intent to take vaccine. Chi-square test shows that participants who have been quarantined during the pandemic have a higher vaccination intention than those have not been quarantined $(P=0.005)$. 
Table 2

Univariate analyses of the association between quarantine vaccination intention, social distancing, psychological distress as well as wellbeing

\begin{tabular}{|llllll|}
\hline & Overall & \multicolumn{2}{c}{ Quarantine duration (Days) } & \multirow{2}{*}{ Pvalue $^{a}$} \\
\cline { 3 - 5 } & & $\mathbf{0}(\mathbf{N}=782)$ & $\mathbf{1 - 7}(\mathbf{N}=69)$ & $>\mathbf{7}(\mathbf{N}=93)$ & \\
\hline Social distancing & $10.7 \pm 3.1$ & $10.1 \pm 3.1$ & $12.7 \pm 2.6^{*}$ & $13.3 \pm 1.9^{*}$ & $<0.001$ \\
\hline Psychological distress & $16.0 \pm 3.9$ & $15.8 \pm 3.9$ & $16.4 \pm 3.9$ & $17.2 \pm 3.8^{*}$ & 0.003 \\
\hline Wellbeing & $16.5 \pm 4.8$ & $16.6 \pm 4.7$ & $16.1 \pm 4.6$ & $15.2 \pm 5.4^{\star}$ & 0.016 \\
\hline Vaccination intention & & & & & 0.005 \\
\hline No & $358(37.9)$ & $315(40.3)$ & $18(26.1)$ & $25(26.9)$ & \\
\hline Yes & $586(62.1)$ & $467(59.7)$ & $51(73.9)$ & $68(73.1)$ & \\
\hline
\end{tabular}

\subsection{Multivariate analyses of the association between quarantine duration and psychological outcomes and vaccination intention}

The multiple linear regression (in Table 3) shows that Quarantine for 1-7 days raises the social distancing by 2.61 (95\% $\mathrm{Cl} 1.90-3.33$ ), while quarantine for $>7$ days increases the social distancing and psychological distress by $3.00(95 \% \mathrm{Cl} 2.37-3.64)$ and $1.03(95 \% \mathrm{Cl}$ $0.22-1.86)$, respectively. However, quarantine for $>7$ days decreases wellbeing by 1.27 ( $95 \% \mathrm{Cl} 0.29-2.26)$. Figure 1 shows the standardized differences of social distancing, psychological distress, and wellbeing. Quarantine duration shows a dose-response relation ( $P$ trend $<0.01$ ), indicating that individuals with longer quarantine duration reported a greater impact on social distancing and psychological distress, and a poorer wellbeing during COVID-19 pandemic. The multiple logistic regression shows that the vaccination intention for the participants who have been quarantined for 1-7 days is 2.16 times higher than those without quarantine after adjusting for gender, age, residence, marriage, education, income, health status, and chronic diseases (in Table 3).

Table 3

Multivariate analyses of association between quarantine duration and vaccination intention, social distancing, psychological distress as well as wellbeing.

\begin{tabular}{|c|c|c|c|c|c|c|c|c|c|}
\hline \multirow{2}{*}{$\begin{array}{l}\text { Quarantine } \\
\text { duration } \\
\text { (Days) }\end{array}$} & \multicolumn{2}{|c|}{ Social distancing } & \multicolumn{2}{|c|}{ Psychological distress } & \multicolumn{2}{|l|}{ Wellbeing } & \multicolumn{3}{|c|}{ Vaccination intention } \\
\hline & $\begin{array}{l}\beta \\
(95 \% \mathrm{Cl})^{\mathrm{a}}\end{array}$ & ${ }_{b}^{\beta}(95 \% \mathrm{Cl})$ & $\underset{\mathrm{a}}{\beta}(95 \% \mathrm{Cl})$ & $\underset{b}{\beta(95 \% \mathrm{Cl})}$ & $\underset{\mathrm{a}}{\beta}(95 \% \mathrm{Cl})$ & $\underset{\mathrm{b}}{\beta}(95 \% \mathrm{Cl})$ & \multicolumn{2}{|c|}{ OR $(95 \% \mathrm{Cl})^{a}$} & $\begin{array}{l}\text { OR } \\
(95 \% \mathrm{Cl})^{\mathrm{b}}\end{array}$ \\
\hline 0 & Reference & Reference & Reference & Reference & Reference & Reference & \multicolumn{2}{|c|}{ Reference } & Reference \\
\hline $1-7$ & $\begin{array}{l}2.56 \\
(1.83- \\
3.28)^{\star \star \star}\end{array}$ & $\begin{array}{l}2.61(1.90- \\
3.33)^{\star \star \star}\end{array}$ & $\begin{array}{l}0.64(-0.32- \\
1.59)\end{array}$ & $\begin{array}{l}0.68(-0.25- \\
1.60)\end{array}$ & $\begin{array}{l}-0.55(-1.72- \\
0.61)\end{array}$ & $\begin{array}{l}-0.61 \\
(-1.72- \\
0.51)\end{array}$ & $\begin{array}{l}1.91 \\
(1.10- \\
3.33)^{\star}\end{array}$ & \multicolumn{2}{|c|}{$\begin{array}{l}2.16(1.22- \\
3.82)^{\star \star}\end{array}$} \\
\hline$>7$ & $\begin{array}{l}3.17 \\
(2.53- \\
3.80)^{\star \star \star}\end{array}$ & $\begin{array}{l}3.00(2.37- \\
3.64)^{\star \star \star}\end{array}$ & $\begin{array}{l}1.41(0.58- \\
2.25)^{\star \star}\end{array}$ & $\begin{array}{l}1.03(0.22- \\
1.86)^{\star}\end{array}$ & $\begin{array}{l}-1.46 \\
(-2.48- \\
0.44)^{\star \star}\end{array}$ & $\begin{array}{l}-1.27 \\
(-2.26- \\
0.29)^{*}\end{array}$ & $\begin{array}{l}1.84 \\
(1.14- \\
2.97)^{\star}\end{array}$ & \multicolumn{2}{|c|}{$\begin{array}{l}1.58(0.96- \\
2.60)\end{array}$} \\
\hline \multicolumn{10}{|c|}{ a Unadjusted model } \\
\hline \multicolumn{10}{|c|}{ b Adjusted for gender, age, residence, marriage, education, income, health status, and chronic diseases. } \\
\hline \multicolumn{10}{|c|}{$* \mathrm{P}<0.05 ; * \star \mathrm{P}<0.01 ; * * * \mathrm{P}<0.001$} \\
\hline
\end{tabular}

\section{Discussion}

The general impacts of quarantine have been established in previous literatures(Brooks et al., 2020; Wang et al., 2021; Wells et al., 2021). However, how the duration of quarantine influences mental health and vaccination intention was less discussed. To our knowledge, this is the first study to explore the impact of quarantine on the psychological outcomes and vaccination intention during the second outbreak of COVID-19 in China. This study used a cross-sectional data collected during the second outbreak of COVID-19 in China to examine the association between quarantine duration and psychological outcomes as well as vaccination intention. Our findings showed that mental health problems still exist in second wave of the COVID-19 epidemic, especially for the participants who have been 
quarantined for more than 7 days. Furthermore, Quarantine duration shows a dose-response relation with social distancing, psychological distress, and wellbeing. In addition, the vaccination intention was relatively lower in second wave of the COVID-19 epidemic than the first wave in China. Participants who have been quarantined for 1-7 days showed a high intention to take a COVID-19 vaccine.

In the present study, we found that quarantine duration was positively associated with increases of social distancing. This result was consistent with previous studies conducted in the initial outbreak of COVID-19(Benke et al., 2020). This may be the reason that the decrease of social contact can contain the spread of COVID-19. Especially the dose-response relation between quarantine duration between social distancing existed in the current study. In addition, the standardized differences of social distancing (Fig. 1) were larger than psychological distress or wellbeing. This result indicated that the decrease of social contact may be the direct one of the most important impacts of quarantine strategies.

We also found that the longer quarantine duration was associated with higher psychological distress and lower wellbeing, supporting a Durkheimian notion that disruption of social networks has deleterious consequences for mental health(Berkman et al., 2000). These findings explained the phenomenon that high prevalence of psychological disorders was reported during the COVID-19 pandemic. For example, the prevalence of anxiety and depression in UK was $24.4 \%$ and $31.4 \%$, respectively(Fancourt et al., 2020). The level of anxiety and depression have gradually increased during lockdown for the participants with pre-existing diagnoses of mental disorders(Fancourt et al., 2020). Importantly, participants who have been quarantined for $>7$ days but not $1-7$ days showed a significant increase of psychological distress and decrease of wellbeing, which extend the previous study about mandatory quarantined status (binary measurement) increased the risk of psychological distress(Wang et al., 2021; Xin et al., 2020). Thus, optimizing the duration of quarantine and providing psychology assistance at appropriate times may be helpful to reduce the level of psychological distress when making quarantine strategies.

Finally, the vaccination intention in the present study $(62.1 \%)$ was lower than previous results reported before the vaccines becoming available(Lazarus et al., 2020; Wang et al., 2020). The scarcity principle may explain this(Bollyky et al., 2020; Persad et al., 2009). The COVID-19 vaccines as one kind of scarce medical resources(Grover et al., 2020), the scarcity of vaccine may increase the demand of the people during the COVID-19 pandemic, especially at the onset of outbreak and the vaccines being unavailable. When the vaccines were available in China on December 31, 2020 and was free of charge to all citizens, the demand of taking vaccination may reduce. In addition, participants who have been quarantined for 1-7 days showed the highest vaccination intention. Thus, taking vaccines should be at the start of quarantine, which may reduce the psychological distress resulting from the longer quarantine duration ( $>7$ days).

There are some limitations in the current study. Firstly, the cross-sectional design limits our ability to draw a causal conclusion. Using longitudinal data may be better to explore the relationship between quarantine and psychological distress as well as vaccination. Secondly, the use of online survey in the current study may limit the sample representativeness. The online survey may a more feasible and flexible way than offline survey during the COVID-19 pandemic. The online survey was also used in previous studies(Li et al., 2021; Wang et al., 2020). Thirdly, some other variables may account for the relationship observed in this study such as loneliness. Previous study showed that loneliness may predict mental symptoms during the COVID-19 pandemic(González-Sanguino et al., 2020; Palgi et al., 2020). A wider range of variables should be considered to control for potential confounding in future studies. Finally, Self-report data was used in the study, memory and recall-biases may be existed.

\section{Conclusions}

In conclusion, this study explored the role of different length of quarantine on psychological outcomes and vaccination intention during the second outbreak of COVID-19 in China. Quarantine with longer duration ( $>7$ days) was associated with the increase of psychological distress and the decrease of wellbeing. While quarantine for 1-7 days related to high vaccination intention. Though quarantine is deemed necessary to limit the spread of COVID-19, the duration of quarantine should be considered by policy-makers when preparing for immunization programs against COVID-19 and preventing psychological disorders during COVID-19 pandemic.

\section{Declarations}

\section{Authors statement}

Lele Chen planned the study, analyzed and interpreted the data, and wrote the manuscript. Yuxin Xia and Dingding Wang collected the data. Lele Chen and Renlai Zhou contributed to the editorial process and revised the manuscript. All authors saw and approved the final 
version.

\section{Declaration of Competing Interest}

The authors declare no conflict of interest.

\section{Acknowledgments}

This research did not receive any specific grant from funding agencies in the public, commercial, or not-for-profit sectors. We would like to express our gratitude for those participants involved in collecting the data.

\section{References}

Benke, C., Autenrieth, L.K., Asselmann, E., Pané-Farré, C.A., 2020. Lockdown, quarantine measures, and social distancing: Associations with depression, anxiety and distress at the beginning of the COVID-19 pandemic among adults from Germany. Psychiatry research 293, 113462

Berkman, L.F., Glass, T., Brissette, I., Seeman, T.E., 2000. From social integration to health: Durkheim in the new millennium. Social science \& medicine 51 (6), 843-857.

Bollyky, T.J., Gostin, L.O., Hamburg, M.A., 2020. The equitable distribution of COVID-19 therapeutics and vaccines. Jama 323 (24), 24622463.

Brooks, S.K., Webster, R.K., Smith, L.E., Woodland, L., Wessely, S., Greenberg, N., Rubin, G.J., 2020. The psychological impact of quarantine and how to reduce it: rapid review of the evidence. The lancet 395 (10227), 912-920.

Daily, C., 2020. Chinese COVID-19 vaccines free to all its citizens: official. Available from: http://subsites.chinadaily.com.cn/nmpa/202012/31/c_579193.htm.(202012-31)

Daily, C., 2021. Shijiazhuang goes on lockdown to curb infection. Available from: https://www.chinadaily.com.cn/a/202101/07/WS5ff65b20a31024ad0baa0f82.html.(202101-07)

Fancourt, D., Steptoe, A., Bu, F., 2020. Trajectories of depression and anxiety during enforced isolation due to COVID-19: Iongitudinal analyses of 59,318 adults in the UK with and without diagnosed mental illness. medRxiv.

George, F.G., 2021. COVID-19: A Year Long and Beyond? China CDC Weekly 3 (8), 157-158.

González-Sanguino, C., Ausín, B., Castellanos, M.Á., Saiz, J., López-Gómez, A., Ugidos, C., Muñoz, M., 2020. Mental health consequences during the initial stage of the 2020 Coronavirus pandemic (COVID-19) in Spain. Brain, behavior, and immunity 87, 172-176.

Grover, S., McClelland, A., Furnham, A., 2020. Preferences for scarce medical resource allocation: Differences between experts and the general public and implications for the COVID-19 pandemic. British journal of health psychology 25 (4), 889-901.

Kim, H.H.-s., Jung, J.H., 2021. Social isolation and psychological distress during the COVID-19 pandemic: A cross-national analysis. The Gerontologist 61 (1), 103-113.

Lazarus, J.V., Ratzan, S.C., Palayew, A., Gostin, L.O., Larson, H.J., Rabin, K., Kimball, S., El-Mohandes, A., 2020. A global survey of potential acceptance of a COVID-19 vaccine. Nature medicine, 1-4.

Li, Q., 2020. An outbreak of NCIP (2019-nCoV) infection in China-wuhan, Hubei province, 2019- 2020. China CDC Weekly 2 (5), 79-80.

Li, W., Zhang, Y., Wang, J., Ozaki, A., Wang, Q., Chen, Y., Jiang, Q., 2021. Association of Home Quarantine and Mental Health Among Teenagers in Wuhan, China, During the COVID-19 Pandemic. JAMA pediatrics.

Luchetti, M., Lee, J.H., Aschwanden, D., Sesker, A., Strickhouser, J.E., Terracciano, A., Sutin, A.R., 2020. The trajectory of loneliness in response to COVID-19. American Psychologist.

Palgi, Y., Shrira, A., Ring, L., Bodner, E., Avidor, S., Bergman, Y., Cohen-Fridel, S., Keisari, S., Hoffman, Y., 2020. The loneliness pandemic: Loneliness and other concomitants of depression, anxiety and their comorbidity during the COVID-19 outbreak. Journal of affective 
disorders.

Pan, A., Liu, L., Wang, C., Guo, H., Hao, X., Wang, Q., Huang, J., He, N., Yu, H., Lin, X., 2020. Association of public health interventions with the epidemiology of the COVID-19 outbreak in Wuhan, China. Jama 323 (19), 1915-1923.

Persad, G., Wertheimer, A., Emanuel, E.J., 2009. Principles for allocation of scarce medical interventions. The lancet 373 (9661), $423-431$.

Pfefferbaum, B., North, C.S., 2020. Mental health and the Covid-19 pandemic. New England Journal of Medicine 383 (6), $510-512$.

Prasetyo, Y.T., Castillo, A.M., Salonga, L.J., Sia, J.A., Seneta, J.A., 2020. Factors affecting perceived effectiveness of COVID-19 prevention measures among Filipinos during enhanced community quarantine in Luzon, Philippines: Integrating Protection Motivation Theory and extended Theory of Planned Behavior. International journal of infectious diseases 99, 312-323.

Sherman, S.M., Smith, L.E., Sim, J., Amlôt, R., Cutts, M., Dasch, H., Rubin, G.J., Sevdalis, N., 2020. COVID-19 vaccination intention in the UK: results from the COVID-19 vaccination acceptability study (CoVAccS), a nationally representative cross-sectional survey. Human vaccines \& immunotherapeutics, 1-10.

Topp, C.W., Østergaard, S.D., Søndergaard, S., Bech, P., 2015. The WHO-5 Well-Being Index: a systematic review of the literature. Psychotherapy and psychosomatics 84 (3), 167-176.

Venkatesh, A., Edirappuli, S., 2020. Social distancing in covid-19: what are the mental health implications? Bmj 369.

Wang, J., Jing, R., Lai, X., Zhang, H., Lyu, Y., Knoll, M.D., Fang, H., 2020. Acceptance of COVID-19 Vaccination during the COVID-19 Pandemic in China. Vaccines 8 (3), 482.

Wang, Y., Shi, L., Que, J., Lu, Q., Liu, L., Lu, Z., Xu, Y., Liu, J., Sun, Y., Meng, S., 2021. The impact of quarantine on mental health status among general population in China during the COVID-19 pandemic. Molecular psychiatry, 1-10.

Wells, C.R., Townsend, J.P., Pandey, A., Moghadas, S.M., Krieger, G., Singer, B., McDonald, R.H., Fitzpatrick, M.C., Galvani, A.P., 2021. Optimal COVID-19 quarantine and testing strategies. Nature Communications 12 (1), 1-9.

Xiang, Y.-T., Yang, Y., Li, W., Zhang, L., Zhang, Q., Cheung, T., Ng, C.H., 2020. Timely mental health care for the 2019 novel coronavirus outbreak is urgently needed. The Lancet Psychiatry 7 (3), 228-229.

Xin, M., Luo, S., She, R., Yu, Y., Li, L., Wang, S., Ma, L., Tao, F., Zhang, J., Zhao, J., 2020. Negative cognitive and psychological correlates of mandatory quarantine during the initial COVID-19 outbreak in China. American Psychologist 75 (5), 607.

Xinhua, 2021. China Focus: China fights COVID-19 resurgence with stepped-up testing, vaccination. Available from:

http://www.xinhuanet.com/english/2021-01/12/c_139662116.htm.(202101-12)

\section{Tables}

Table1 Characteristics of the study population stratified by quarantine duration 


\begin{tabular}{|c|c|c|c|c|c|}
\hline \multirow[b]{3}{*}{ nder } & \multirow[t]{2}{*}{ Overall N(\%) } & \multicolumn{3}{|c|}{ Quarantine duration (Days, N, \%) } & \multirow[t]{2}{*}{$P$ value ${ }^{\mathrm{a}}$} \\
\hline & & $0(\mathrm{~N}=782)$ & $1-7(\mathrm{~N}=69)$ & $>7(\mathrm{~N}=93)$ & \\
\hline & & & & & 0.150 \\
\hline ile & $256(27.1)$ & $220(85.9)$ & $12(4.7)$ & $24(9.4)$ & \\
\hline male & 688(72.9) & $562(81.7)$ & $57(8.3)$ & $69(10.0)$ & \\
\hline e, mean(SD), years & $32.7 \pm 13.0$ & $33.4 \pm 13.3$ & $32.7 \pm 12.3$ & $27.3 \pm 9.6$ & $<0.001$ \\
\hline sidence & & & & & 0.099 \\
\hline ban & $621(65.8)$ & $511(82.3)$ & $53(8.5)$ & $57(9.2)$ & \\
\hline ral & $323(34.2)$ & 271(83.9) & $16(5.0)$ & $36(11.1)$ & \\
\hline irriage & & & & & 0.001 \\
\hline married & 508(53.8) & 406(79.9) & $35(6.9)$ & 67(13.2) & \\
\hline irried & $436(46.2)$ & $376(86.2)$ & $34(7.8)$ & $26(6.0)$ & \\
\hline ucation & & & & & 0.903 \\
\hline condary and below & 104(11.0) & 87(83.7) & $8(7.7)$ & $9(8.6)$ & \\
\hline rtiary & $840(89.0)$ & $695(82.7)$ & $61(7.3)$ & $84(10.0)$ & \\
\hline snthly per-capita inc & ome (Yuan) & & $<0.001$ & & \\
\hline 000 & $140(14.8)$ & 111(79.3) & $9(6.4)$ & $20(14.3)$ & \\
\hline $01-3000$ & $286(30.3)$ & $224(78.3)$ & $20(7.0)$ & $42(14.7)$ & \\
\hline $01-5000$ & $225(23.8)$ & $185(82.2)$ & $19(8.4)$ & $21(9.3)$ & \\
\hline 000 & $293(31.1)$ & $262(89.4)$ & $21(7.2)$ & $10(3.4)$ & \\
\hline If-reported health & & & & & 0.661 \\
\hline $\mathrm{ir} /$ Poor & $271(28.7)$ & $231(85.2)$ & $18(6.6)$ & $22(8.2)$ & \\
\hline od & $482(51.1)$ & $396(82.2)$ & $34(7.1)$ & $52(10.8)$ & \\
\hline ry good & $191(20.2)$ & $155(81.2)$ & 17(8.9) & $19(9.9)$ & \\
\hline ronic diseases & & & & & 0.155 \\
\hline 1 & $861(91.2)$ & $707(82.1)$ & $65(7.5)$ & $89(10.4)$ & \\
\hline $\mathrm{s}$ & $83(8.8)$ & $75(90.4)$ & $4(4.8)$ & $4(4.8)$ & \\
\hline
\end{tabular}

Note: ${ }^{\text {a }}$ F-test or $\chi 2$ tests as appropriate.

Table 2 Univariate analyses of the association between quarantine vaccination intention, social distancing, psychological distress as well as wellbeing

\begin{tabular}{lccccc}
\hline & Overall & \multicolumn{3}{c}{ Quarantine duration (Days) } & \multirow{2}{*}{$P$ value $^{a}$} \\
\cline { 3 - 5 } & & $0(\mathrm{~N}=782)$ & $1-7(\mathrm{~N}=69)$ & $>7(\mathrm{~N}=93)$ & \\
\hline Social distancing & $10.7 \pm 3.1$ & $10.1 \pm 3.1$ & $12.7 \pm 2.6^{*}$ & $13.3 \pm 1.9^{*}$ & $<0.001$ \\
\hline Psychological distress & $16.0 \pm 3.9$ & $15.8 \pm 3.9$ & $16.4 \pm 3.9$ & $17.2 \pm 3.8^{*}$ & 0.003 \\
Wellbeing & $16.5 \pm 4.8$ & $16.6 \pm 4.7$ & $16.1 \pm 4.6$ & $15.2 \pm 5.4^{*}$ & 0.016 \\
\hline Vaccination intention & & & & & 0.005 \\
No & $358(37.9)$ & $315(40.3)$ & $18(26.1)$ & $25(26.9)$ & \\
Yes & $586(62.1)$ & $467(59.7)$ & $51(73.9)$ & $68(73.1)$ & \\
\hline
\end{tabular}

Note: ${ }^{\text {a }}$ F-test or $\chi 2$ tests as appropriate. ${ }^{*}$ The comparison is declared significant when using the least significant difference (LSD) test and selecting the participants without isolation as reference group.

Table 3 Multivariate analyses of association between quarantine duration and vaccination intention, social distancing, psychological distress as well as wellbeing.

\begin{tabular}{|c|c|c|c|c|c|c|c|c|c|}
\hline \multirow{2}{*}{$\begin{array}{l}\text { Quarantine } \\
\text { duration } \\
\text { (Days) }\end{array}$} & \multicolumn{2}{|c|}{ Social distancing } & \multicolumn{2}{|c|}{ Psychological distress } & \multicolumn{2}{|c|}{ Wellbeing } & \multicolumn{3}{|c|}{ Vaccination intention } \\
\hline & $\beta(95 \% C I)^{a}$ & $\beta(95 \% C I) b$ & $\beta(95 \% \text { CI })^{a}$ & $\beta(95 \% C I)^{b}$ & $\beta(95 \% C I)^{a}$ & $\beta(95 \% \mathrm{CI})^{b}$ & $\begin{array}{l}\text { OR } \\
\text { (95 }\end{array}$ & CI) ${ }^{a}$ & $\begin{array}{l}\text { OR } \\
(95 \% \mathrm{CI})^{\mathrm{b}}\end{array}$ \\
\hline 0 & Reference & Reference & Reference & Reference & Reference & Reference & Ref & ence & Reference \\
\hline $1-7$ & $\begin{array}{l}2.56(1.83- \\
3.28) * * *\end{array}$ & $\begin{array}{l}2.61(1.90- \\
3.33) * * *\end{array}$ & $\begin{array}{l}0.64(-0.32- \\
1.59)\end{array}$ & $\begin{array}{l}0.68(-0.25- \\
1.60)\end{array}$ & $\begin{array}{l}-0.55(-1.72- \\
0.61)\end{array}$ & $\begin{array}{l}-0.61(-1.72- \\
0.51)\end{array}$ & $\begin{array}{l}1.91 \\
(1.10- \\
3.33)^{*}\end{array}$ & $\begin{array}{l}2.16 \\
3.82)\end{array}$ & $1.22-$ \\
\hline
\end{tabular}

a Unadjusted model

$\mathrm{b}$ Adjusted for gender, age, residence, marriage, education, income, health status, and chronic diseases.

${ }^{*} \mathrm{P}<0.05 ;{ }^{* *} \mathrm{P}<0.01 ; * * * \mathrm{P}<0.001$ 


\section{Figures}

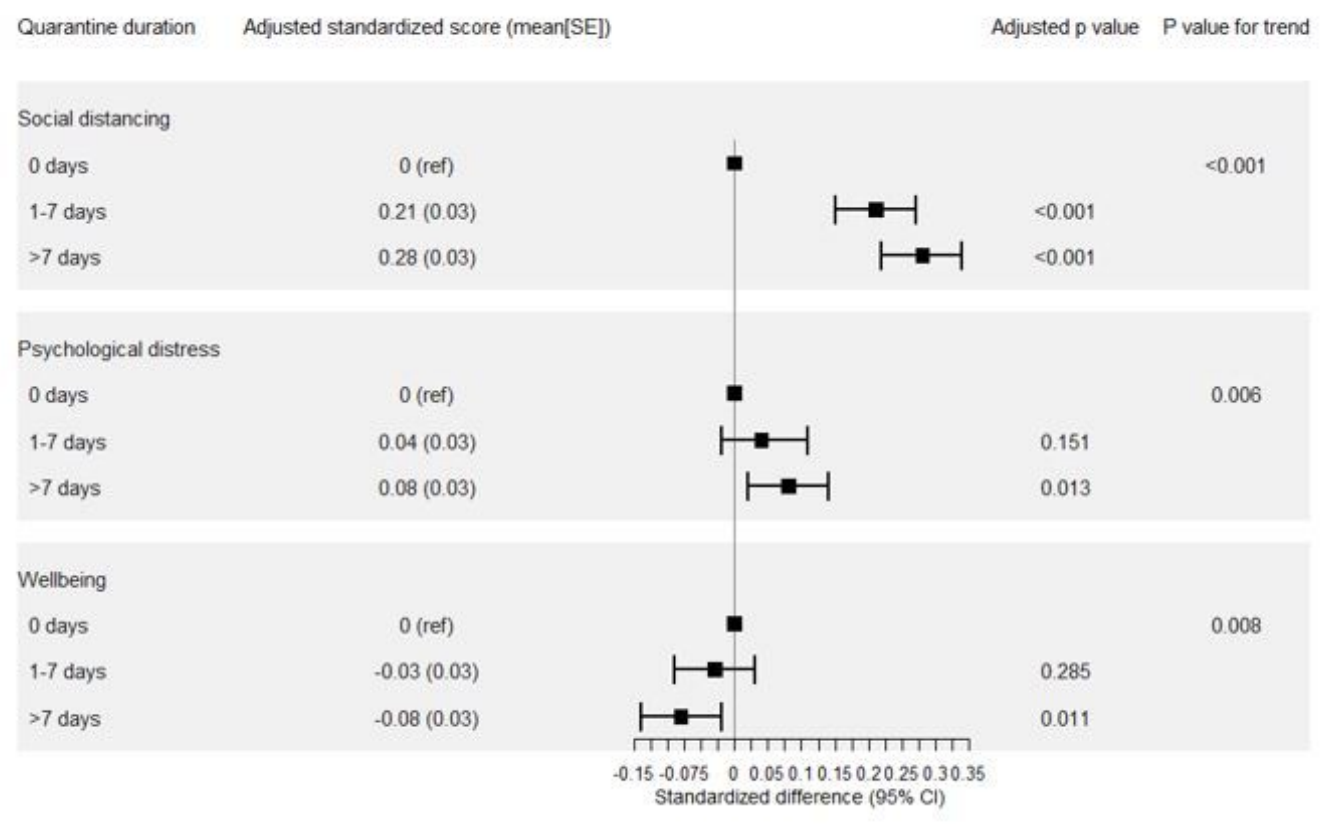

\section{Figure 1}

The adjusted standardized score of social distancing, psychological distress, and wellbeing was derived from linear regression, adjusted for gender, age, residence, marriage, education, income, health status, and chronic diseases. 